\title{
Leaf trait differences between 97 pairs of invasive and native plants across China: effects of identities of both the invasive and native species
}

\author{
Ming-Chao Liu ${ }^{{ }^{*}}$, Ting-Fa Dong ${ }^{2^{*}}$, Wei-Wei Feng' ${ }^{1}$, Bo Qu', \\ De-Liang Kong', Mark van Kleunen ${ }^{3,4}$, Yu-Long Feng'
}

I Liaoning Key Laboratory for Biological Invasions and Global Changes, College of Bioscience and Biotechnology, Shenyang Agricultural University, Shenyang, Liaoning Province 110866, China 2 Key Laboratory of Southwest China Wildlife Resources Conservation, Ministry of Education, and College of Life Sciences, China West Normal University, Nanchong, Sichuan Province 637009, China 3 Department of Biology, University of Konstanz, Konstanz, Germany 4 Zhejiang Provincial Key Laboratory of Plant Evolutionary Ecology and Conservation, Taizhou University, Taizhou 318000, China

Corresponding author: Yu-Long Feng (fyl@syau.edu.cn)

Academic editor: Ruth Hufbauer | Received 10 July 2021 | Accepted 27 October 2021 | Published 6 January 2022

Citation: Liu M-C, Dong T-F, Feng W-W, Qu B, Kong D-L, van Kleunen M, Feng Y-L (2022) Leaf trait differences between 97 pairs of invasive and native plants across China: effects of identities of both the invasive and native species. NeoBiota 71: 1-22. https://doi.org/10.3897/neobiota.71.71385

\begin{abstract}
Many studies have attempted to test whether certain leaf traits are associated with invasive plants, resulting in discrepant conclusions that may be due to species-specificity. However, no effort has been made to test for effects of species identity on invasive-native comparisons. Here, we compared 20 leaf traits between 97 pairs of invasive and native plant species in seven disturbed sites along a southwest-to-northeast transect in China using phylogenetically controlled within-study meta-analyses. The invasive relative to the native species on average had significantly higher leaf nutrients concentrations, photosynthetic rates, photosynthetic nutrients- and energy-use efficiencies, leaf litter decomposition rates, and lower payback time and carbon-to-nitrogen ratios. However, these differences disappeared when comparing weakly invasive species with co-occurring natives and when comparing invasives with co-occurring widespread dominant natives. Furthermore, the magnitudes of the differences in some traits decreased or even reversed when a random subset of strongly to moderately invasive species was excluded from the species pool. Removing rare to common natives produced the same effect, while exclusion of weakly to moderately invasives and dominant to common natives enhanced the differences. Our study indicates that the results of invasivenative comparisons are species-specific, providing a possible explanation for discrepant results in previous
\end{abstract}

* Ming-Chao Liu and Ting-Fa Dong contributed equally to this work

Copyright Ming-Chao Liu et al. This is an open access article distributed under the terms of the Creative Commons Attribution License (CC BY 4.0), which permits unrestricted use, distribution, and reproduction in any medium, provided the original author and source are credited. 
studies, such that we may be unable to detect general patterns regarding traits promoting exotic plant invasions through multi-species comparisons.

\section{Keywords}

Invasive plant species, leaf functional traits, multiple species experimental comparisons, native species, species identity, within-study meta-analysis

\section{Introduction}

Thousands of plant species have established wild populations outside their native regions (van Kleunen et al. 2015a), and the number is still increasing (Seebens et al. 2017). Some of these non-native species spread rapidly and can reach abundances much higher than those of most co-occurring native species or their native conspecifics (Inderjit et al. 2011; Zheng et al. 2015; Zhao et al. 2020). The mechanisms underlying such non-native plant invasions have become one of the major topics in biology (Richardson and Pyšek 2006; Feng et al. 2009; van Kleunen et al. 2010; Li et al. 2015; Hulme and Bernard-Verdier 2018). As a group, these invasive non-native (hereafter invasive) species may have distinct traits that allow them to compete with or even outcompete co-occurring native species (van Kleunen et al. 2015b; Huang et al. 2020).

In order to disentangle the traits associated with invasive plants, many case studies have compared traits of invasive species with both native and non-invasive exotic species (McDowell 2002; Feng et al. 2007; Feng 2008; Wang et al. 2013; Liu and van Kleunen 2017; Liu et al. 2017). However, the conclusions were inconsistent or even contradictory among these studies, and no general pattern was evident. For example, Feng et al. (2007) found that the invasive plant Buddleja davidii has a higher specific leaf area than co-occurring native Berberis vulgaris and Crataegus monogyna, but similar to native Cornus sanguinea, Sambucus nigra and Betula pendula, and a higher leaf photosynthetic rate than the native plants except $B$. pendula. These results indicate that identities of the focal species strongly determine whether invasive-native differences in leaf functional traits were detectable.

Many researchers have attempted to obtain a conclusion with universal significance for traits associated with invasiveness (Baruch and Goldstein 1999; Leishman et al. 2007; Heberling and Fridley 2013; Divíšek et al. 2018; Huang et al. 2020). Unfortunately, there were still large variations in the conclusions from the above-mentioned multi-species (dozens of or more) comparisons. For example, the differences in seven of the 11 traits (64\%) between invasive and native species were inconsistent (even opposite) among multi-species comparisons (Suppl. material 2: Table S1). Besides the multi-species experimental comparisons, five studies summarized the results from published case studies (Daehler 2003; Leishman et al. 2007; Pyšek and Richardson 2007; van Kleunen et al. 2010; Castro-Díez et al. 2014). In total, five traits were compared in more than one of these reviews (Suppl. material 2: Table S1), and differences between invasive and native species in four of the five traits $(80 \%)$ were inconsistent 
among these reviews. Combining the multi-species comparisons and the reviews, we found that 14 traits were compared in more than one study, and the conclusions were inconsistent or opposite in nine of the 14 traits (64\%) among these studies. The high frequency of the inconsistent results in these comparisons indicates that it is difficult to find general conclusions regarding traits associated with invasive species.

There are many reasons for discrepant conclusions among comparative studies between invasive and native species. For example, conclusions generated from reviews may be confounded by publication biases, which generally overestimate trait advantage of invasive species (Rosenberg et al. 2000; Leimu and Koricheva 2004; Koricheva and Gurevitch 2014). The conclusions of multi-species experimental studies may also be influenced by environmental factors such as disturbance regimes (Leishman et al. 2007). Trait differences between invasive and native species may be environment-dependent (Hulme and Bernard-Verdier 2018). However, the most important and often overlooked influencing factor may be the inherent trait characteristics of the invasive and native species compared. The differences between invasive and native species may vary with the changes in the species compared (McDowell 2002; Feng et al. 2007; Liu et al. 2017). Until now, however, no effort has been made to explicitly test the effect of species identity on invasive-native trait comparisons.

To address this problem, we compared 97 pairs of invasive and co-occurring native plant species at seven sites in six provinces from tropical to mid-temperate zones of China. The invasive species were divided into three categories according to their invasiveness (invasion status) in China, and the native species were also grouped into three categories according to their distribution and abundances in China. We focused on 20 leaf functional traits, which greatly influence plant resource capture ability and use-efficiency, and therefore plant growth and reproduction. We firstly determined the overall differences between the invasive and native species using a within-study meta-analytical approach, and then tested for the effect of species identity on the differences between the invasive and native species. We hypothesize that (1) the differences at least in some traits may be significant when the strongly to moderately invasive species are compared with their cooccurring natives, but not significant when the weakly invasive species are compared with their co-occurring natives. (2) Similarly, the differences may be significant when the rare to common natives are compared with their co-occurring invasives, but not significant when the widespread dominant natives are compared with their co-occurring invasives. (3) The magnitudes of the differences may decrease when we gradually exclude a random subset of strongly to moderately invasive species (also including the natives paired with them) from the species pool (97 pairs), while exclusion of weakly invasive species may enhance the differences. (4) Similarly, the magnitudes of the differences may decrease when we gradually exclude a random subset of rare to common natives from the species pool, while exclusion of widespread dominant natives may enhance the differences. (5) The magnitudes of the differences may be smaller when the invasives are compared with the natives that are invasive elsewhere than with the natives that are non-invasive elsewhere. To the best of our knowledge, no study has addressed the aforementioned issues, although many have compared traits of invasive and native species. 


\section{Materials and methods}

\section{Study sites and plant species}

This study was conducted at seven sites in six provinces along the southwest-to-northeast axis of China. We selected two sites in Heilongjiang Province and one site in each of the other five provinces (Suppl. material 2: Table S2). All sites were disturbed severely and had many invasive plant species. In each site, the vegetation was mainly composed of mixed herbs and shrubs with scattered trees (see Suppl. material 3: Table S3 for the detail habitat of each species pair). The sites spanned $24^{\circ}$ in latitude $\left(21^{\circ} 56^{\prime}-\right.$ $\left.45^{\circ} 39^{\prime} \mathrm{N}\right)$ and $28^{\circ}$ in longitude $\left(101^{\circ} 15^{\prime}-129^{\circ} 34^{\prime} \mathrm{E}\right)$, including tropical, subtropical and temperate zones (Fig. 1). The linear distance between the most southwestern and northeastern sites was $-3600 \mathrm{~km}$.

In each site (at least $2000 \mathrm{~m}^{2}$ with irregular shape), we first located as many invasive plant species (5-23) as possible, and then tried to select a taxonomically related (congeneric or confamilial) and/or functionally similar (with the same growth form, e.g. herb vs herb) native species near each invader $(<2 \mathrm{~m})$, forming a comparable species pair (three replicates for each species). Taxonomically related and/ or functionally similar natives may share more similar growth strategies with the invasives, and thus increasing the comparability. For some of the invasive species, however, taxonomically related and/or functionally similar natives were not found, in which case the invasives were compared with their nearby randomly chosen natives, respectively (14 pairs, see Suppl. material 3: Table S3). To reduce confounding effects of phylogenetic distance between the invasive and native species in each species pair on the comparative results, phylogenetic relatedness was controlled when analyzing the differences between the invasive and native species (see statistical analysis section). Environmental heterogeneities within and especially among the sites were large, which inevitably influenced the variances within and between species categories (invasives vs. natives). Thus, we used a paired-species comparison approach (within-study meta-analysis) in order to decrease the confounding effects of environmental heterogeneities on species comparative results.

In total we compared 97 species pairs, including 56 invasives ( 35 annual herbs, 13 perennial herbs, 2 shrubs, 2 trees and 4 climbers) and 60 natives (23 annual herbs, 24 perennial herbs, 2 shrubs, 6 trees and 5 climbers) (Suppl. material 3: Table S3). The invasives were grouped into three categories according to their degree of invasiveness (distribution and ecological impacts; Ma 2013): 15 species with strong invasiveness, 17 with moderate invasiveness, and 24 with weak invasiveness, which represented $44.1 \%, 24.6 \%$, and $14.5 \%$ of the total species in each category in China, respectively (Suppl. material 3: Table S3). The strongly invasive species were distributed in more than one geographic area, and had caused tremendous ecological and/or economic losses in China (Ma 2013). The moderately invasive species were also distributed in more than one geographic area but with less ecological and/or economic losses compared with the former (Ma 2013). The weakly 
invasive species were locally distributed and caused minor ecological and/or economic losses in China (Ma 2013). The natives were grouped into three categories according to their abundance and distribution in China: 11 widespread dominants, 10 commons, and 39 rares [Li 1998; Flora of China (http://foc.eflora.cn/)]. This classification was based on the intrinsic characteristics of the natives, and the result of this classification had nothing to do with whether invasive species exist or not. In our study sites, the existing states of the invasive and native species were consistent with above classifications, i.e., strongly invasive plants and widespread natives had higher abundances than weakly invasives and rare natives, respectively. The natives were also separated into two categories according to their invasive elsewhere: 11 invasive elsewhere and 49 non-invasive elsewhere (http://www.griis.org/sources. php; and the references given in Suppl. material 3: Table S3). Some invasives were measured in more than one site.

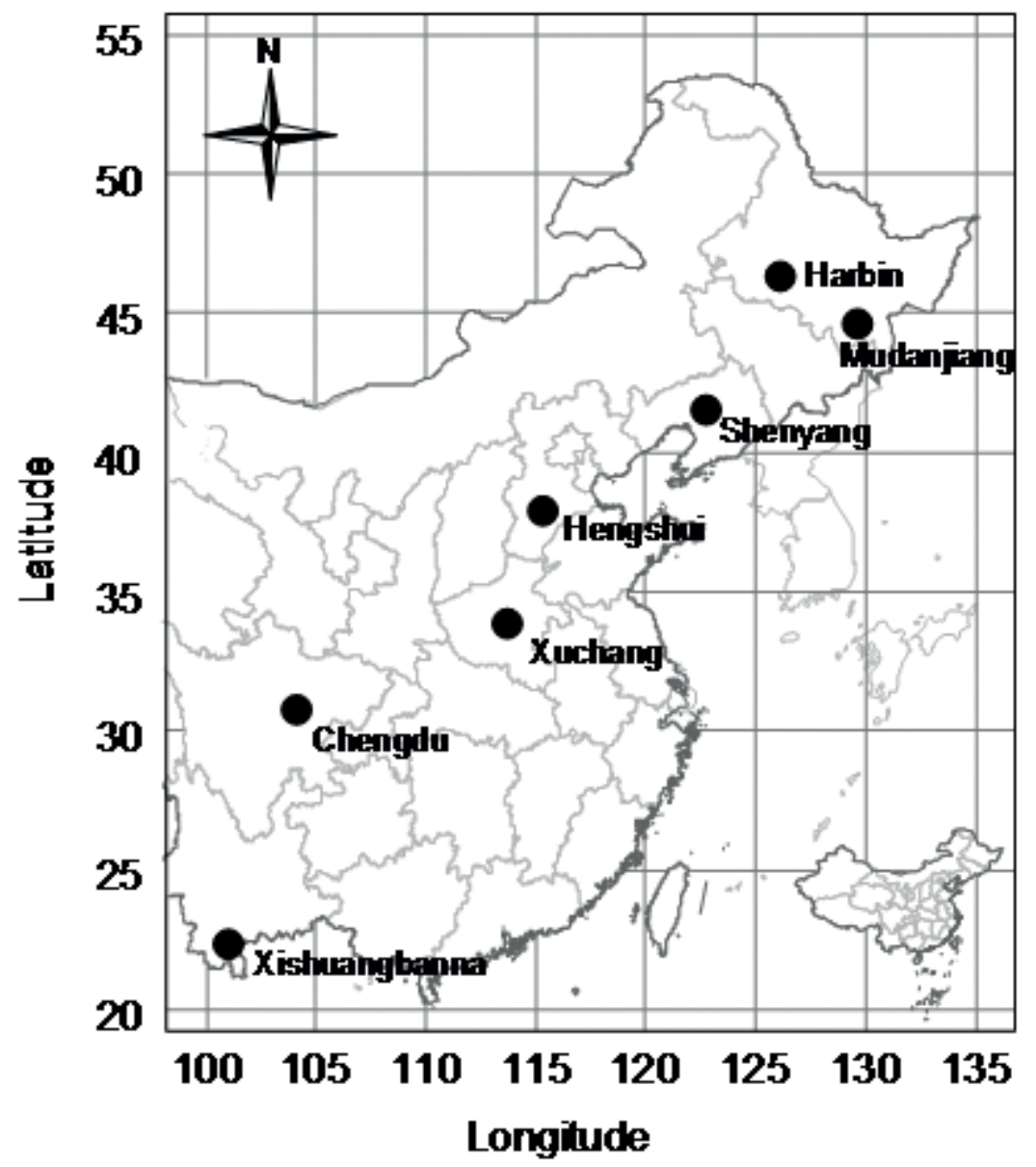

Figure I. Sample sites spanning $24^{\circ}$ latitudes from tropical to temperate zones in China. 


\section{Measurements}

For each of the 97 species pairs, we measured six individuals of the invasive and native species (582 individuals in total). Light-saturated photosynthetic rate $\left(P_{\max }\right)$, stomatal conductance $\left(G_{\mathrm{s}}\right)$ and dark respiration rate $\left(R_{\mathrm{d}}\right)$ were measured in the morning on the youngest fully expanded leaves using a Li-6400 Portable Photosynthesis System (LiCor, Lincoln, NE, USA). Leaf temperature was set to $30^{\circ} \mathrm{C}$, photosynthetic photon flux density to $2000 \mu \mathrm{mol} \mathrm{m} \mathrm{m}^{-2} \mathrm{~s}^{-1}$, and $\mathrm{CO}_{2}$ concentration in the reference chamber was $380 \mu \mathrm{mol} \mathrm{mol}^{-1}$. We recorded $P_{\text {max }}\left(\mu \mathrm{mol} \mathrm{m} \mathrm{s}^{-2}\right)$ and $G_{\mathrm{s}}\left(\mathrm{mol} \mathrm{m}^{-2} \mathrm{~s}^{-1}\right)$ when their values had become stable, then we switched off the light source and recorded $R_{\mathrm{d}}\left(\mu \mathrm{mol} \mathrm{m} \mathrm{m}^{-2} \mathrm{~s}^{-1}\right)$ when its value had become stable. All the measurements were done in July and August, when the plants were at the vigorous growth stage.

For each leaf that was used for photosynthesis measurement, we measured its average thickness using a microcalliper at more than 10 points (avoiding veins), and singleside area using a Li-3000C Leaf Area Meter (Li-Cor, Lincoln, NE, USA). Then the leaf was oven-dried at $60{ }^{\circ} \mathrm{C}$ to constant weight, and weighed. Specific leaf area (SLA, $\mathrm{cm}^{2} \mathrm{mg}^{-1}$ ) was calculated as the ratio of leaf area to dry mass, and leaf-tissue density ( $\mathrm{g}$ $\mathrm{cm}^{-3}$ ) as the ratio of leaf mass to volume, i.e., leaf mass / (thickness $\times$ area). Mass-based $P_{\text {max }}\left(\mu \mathrm{mol} \mathrm{g} \mathrm{s}^{-1}\right), G_{\mathrm{s}}\left(\mathrm{mmol} \mathrm{g}^{-1} \mathrm{~s}^{-1}\right)$ and $R_{\mathrm{d}}\left(\mu \mathrm{mol} \mathrm{g}^{-1} \mathrm{~s}^{-1}\right)$ were calculated from their measured area-based values and SLA.

For measuring leaf-element concentrations, 6 to 30 mature leaves around the leaf used for measuring photosynthesis were also collected from each sample plant. Leafcarbon $\left(C_{\mathrm{m}}, \mathrm{mg} \mathrm{g}^{-1}\right)$ and nitrogen $\left(N_{\mathrm{m}}, \mathrm{mg} \mathrm{g}^{-1}\right)$ concentrations were determined using an Elementar Vario MAX CN analyser (Elementar Analysensysteme, GmbH, Germany). Leaf-phosphorus $\left(P_{\mathrm{m}}, \mathrm{mg} \mathrm{g}^{-1}\right)$ and potassium $\left(K_{\mathrm{m}}, \mathrm{mg} \mathrm{g}^{-1}\right)$ concentrations were determined using an IRIS advantage-ER inductively coupled plasma atomic-emission spectrometer (ICP-AES, Thermo Jarrell Ash Corp., MA, USA). Due to a limited amount of leaf material, $C_{\mathrm{m}}$ and $N_{\mathrm{m}}$ were not measured for seven of the 97 species pairs, and $P_{\mathrm{m}}$ and $K_{\mathrm{m}}$ were not measured for 17 of the species pairs (Suppl. material 3: Table S3).

Leaf-construction cost (CC, g glucose $\left.\mathrm{g}^{-1}\right)$ was calculated as $(5.39 \times$ carbon concentration - 1191) / 1000, following Feng et al. (2007). Photosynthetic nitrogen-use efficiency (PNUE, $\mu \mathrm{mol} \mathrm{g}^{-1} \mathrm{~s}^{-1}$ ), photosynthetic phosphorus-use efficiency (PPUE, $\mu \mathrm{mol}$ $\mathrm{g}^{-1} \mathrm{~s}^{-1}$ ), photosynthetic potassium-use efficiency (PKUE, $\mu \mathrm{mol} \mathrm{g} \mathrm{g}^{-1} \mathrm{~s}^{-1}$ ), photosynthetic

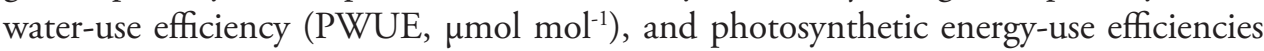
(PEUE, $\mu \mathrm{mol} \mathrm{g} \mathrm{s}^{-1}$ ) were calculated as the ratios of $P_{\max }$ to $N_{\mathrm{m}}, P_{\mathrm{m}}, K_{\mathrm{m}}, G_{\mathrm{s}}$, and CC, respectively. Payback time (PT, d) of leaf-construction costs was calculated as $\left(\mathrm{CC} \times 10^{6}\right) /$ $\left[12 \times\left(P_{\max } / 2 \times 12 \times 3600-R_{\mathrm{d}} \times 12 \times 3600\right) \times 180 / 72\right]$, following Feng et al. $(2011)$.

For measuring leaf-decomposition rate, we collected the remaining functional mature leaves of each sample plant and the mature leaves from nearby conspecific plants, which were oven-dried at $60^{\circ} \mathrm{C}$ to constant weight and stored in desiccators until used. Enough leaf material for the decomposition experiment was available for 73 of the 97 species pairs. We weighed 1 to $2 \mathrm{~g}$ of dry leaves of each sample plant, and put the leaves into $15 \times 20 \mathrm{~cm}$ nylon mesh bags that had $1 \mathrm{~mm}$ holes. In August (rainy season) the decomposition bags (438 in total) were put on the soil surface, after removal of natu- 
ral litter, under a primary tropical rainforest in the Xishuangbanna Tropical Botanical Garden of the Chinese Academy of Sciences $\left(21^{\circ} 41^{\prime} \mathrm{N}, 101^{\circ} 25^{\prime} \mathrm{E}\right.$, a.s.1. $\left.570 \mathrm{~m}\right)$, Yunnan Province, southwest China. The three bags containing the leaves of each invasive species were put adjacent to the ones containing the leaves of its native counterpart species in order to decrease variation due to environmental heterogeneity. The pair-wise bags were placed randomly and at least $20 \mathrm{~cm}$ apart from one another. In September, the bags were collected, and the remaining leaves were washed gently, oven-dried at $60{ }^{\circ} \mathrm{C}$ to constant weight, and weighed. The concentrations of $\mathrm{C}$ and $\mathrm{N}$ were determined using an Elementar Vario MAX CN analyser. For 28 of the 73 species pairs, the remaining leaf material was insufficient for determination of $C_{\mathrm{m}}$ and $N_{\mathrm{m}}$. Mass- (Loss-M; \%), carbon(Loss-C; \%), and nitrogen-loss (Loss-N; \%) rates of the leaves were calculated as (initial value - final value) / initial value.

In our decomposition experiment, mature leaves instead of leaf litters were used as it was impossible to collect enough leaf litter for these species. Strong disturbance of the study sites, differences in progress of leaf senescence and abscission among the species, and the great distance among the study sites all obstructed leaf-litter collection. Several previous decomposition experiments also used oven-dried mature leaves, and found that decomposition rates are not significantly different between dried green mature leaves and senescent yellow leaves (Leung 1986; Tam et al. 1990). It has been documented that nutrient concentrations in leaf litter are positively correlated with those in mature leaves, and that the latter better explain litter decomposition (Kobe et al. 2005; Cornwell et al. 2008; Bakker et al. 2011). Thus, interspecific differences in decomposition rate of mature leaves are likely to reflect the differences in decomposition rate of naturally senesced leaf litter (Bakker et al. 2011).

\section{Statistical analyses}

The overall differences between the invasive and native species in the 20 leaf traits were tested using within-study meta-analyses (van Kleunen et al. 2011; Huang et al. 2020). We firstly calculated the effect size (Hedges' $d$ ) and the corresponding sampling variance $\left(v_{d}\right)$ of each trait for each species pair using the escalc function in $\mathrm{R}$ package metafor (Viechtbauer 2010). Hedges' $d$ was calculated as:

$$
d=\frac{\left(\bar{X}_{i}-\bar{X}_{n}\right)}{S} J
$$

where $\bar{X}_{i}$ and $\bar{X}_{n}$ are trait means of the invasive and native species, respectively; $S$ is the pooled standard deviation of the invasive and native species; and $J$ is a weighting factor based on the number of replicates. $S$ and $J$ were calculated as:

$$
S=\sqrt{\frac{\left(N_{i}-1\right)\left(S_{i}\right)^{2}+\left(N_{n}-1\right)\left(S_{n}\right)^{2}}{N_{i}+N_{n}-2}}
$$




$$
J=1-\frac{3}{4\left(N_{i}+N_{n}-2\right)-1}
$$

where $N_{i}$ and $N_{n}$ are the numbers of the replicates of the invasive and native species (here 3 for all species), respectively; $S_{i}$ and $S_{n}$ are the standard deviations of the invasive and native species, respectively. The sampling variance of Hedges' $d$ was calculated as:

$$
v_{d}=\frac{N_{i}+N_{n}}{N_{i} N_{n}}+\frac{d^{2}}{2\left(N_{i}+N_{n}\right)}
$$

We then calculated the weighted mean effect size $\left(d^{++}\right)$(using reciprocal of $v_{\mathrm{d}}$ ) and 95\% confidence interval (CI) of each trait for all species pairs using the random-effects model of the rma.mv function in $\mathrm{R}$ package metafor (Viechtbauer 2010). The overall difference was significant if the $95 \%$ CI did not include zero. The value of $d>0$ indicates that the invasive species is higher in the trait than its native counterpart in the same species pair.

To determine whether the overall difference between the invasive and native species was affected by other factors besides sampling error, we tested for total heterogeneity in effect size of each trait among all species pairs $\left(Q_{\mathrm{T}}\right)$. If $Q_{\mathrm{T}}$ was significant $(P<$ 0.05 ) for a trait, we conducted the mixed-effects multivariate models using the rma.mv function to test for effects of other factors on the overall difference in this trait. In the mixed-effects models, $Q_{T}$ was separated into two components: structural model $\left(Q_{\mathrm{M}}\right)$ and unexplained heterogeneity $\left(Q_{\mathrm{E}}\right)$, and all were tested using the $Q$-test $(V i e c h t b a u e r$ 2010). The factors included invasiveness of the invasive species (strong, moderate, and weak), and abundances (dominant, common, and rare) and invasive elsewhere (invasive and non-invasive elsewhere) of the native species.

To further determine the effects of the identities of both the invasive (invasiveness) and native (abundance) species on their overall differences, we compared invasive and native species separately from many subsets of species pairs. The subsets of species pairs were created by gradually and randomly removing invasives with different invasiveness (or natives with different abundances) from the species pool (4-10 pairs each time according to species number in each category; see Figs 4, 5). To increase the proportion of strongly invasive species in each subset of species pairs (until 100\%), we first removed weakly invasive species and then moderately invasive species. Similarly, to increase the proportion of weakly invasive species in each subset of species pairs (until 100\%), we first removed strongly invasive species and then moderately invasive species. To increase the proportion of rare natives in each subset of species pairs (until $100 \%$ ), we first removed widespread dominant natives and then common natives, while removed rare natives and then common natives in order to increase the proportion of dominant natives in each subset of species pairs (until 100\%).

Phylogenetic distance between the invasive and native species in each species pair, latitude and altitude of each study site, and the times for which each invasive species was compared with natives were used as random factors in our analyses. To obtain the phylogenetic 
distance, we constructed a phylogenetic tree using ribosomal DNA internal transcribed spacer (ITS1 and ITS2) from GenBank (https://www.ncbi.nlm.nih.gov/). For 10 of the 116 species, the ITS sequences were not found in GenBank, and were substituted by those of their congeners, respectively: Axonopus compressus by A. capillaris, Bidens maximovicziana by B. cernua, Buxus megistophylla by B. microphylla subsp. Sinica, Clinopodium sp. by $C$. gracile, Pistia stratiotes by Pinellia ternata (confamilial), Plantago asiatica by P. major, Polygonum strigosum by $P$. thunbergii (syn. Persicaria thunbergii), Pueraria edulis by $P$. montana var. lobata, Rheum sp. by $R$. altaicum, Rorippa globosa by $R$. indica). This did not influence the results in such large-scale phylogeny. We first aligned the DNA sequences using MUSCLE in MEGA (version 6.06; Tamura et al. 2013), then constructed a maximum-likelihood tree and tested it with 100 bootstrap replicates. Podocarpus macrophyllus var. maki (gymnosperm) was used as an outgroup to root the tree (Suppl. material 1: Fig. S1). Finally, we calculated the phylogenetic distance between the invasive and native species in each species pair using cophenetic function in the R package ape (Swenson 2014).

All analyses were performed in R 3.5.2 (R Core Team 2018).

\section{Results}

\section{Overall differences between the invasive and native species}

Based on our phylogenetically controlled within-study meta-analyses, the invasive relative to the native species on average had significantly higher leaf-nitrogen concentrations $\left(N_{\mathrm{m}}\right)$, light-saturated photosynthetic rates $\left(P_{\max }\right)$, photosynthetic energy- (PEUE), nitrogen- (PNUE), phosphorus- (PPUE), and potassium-use (PKUE) efficiencies, leaf carbon- (Loss-C) and nitrogen- (Loss-N) loss rates (Fig. 2). Leaf-phosphorus concentrations $\left(P_{\mathrm{m}} ; 95 \%\right.$ CI: -0.016 to 0.623$)$ and stomatal conductance $\left(G_{s} ; 95 \%\right.$ CI: -0.027 to 0.531 ) were marginally higher for the invasives. In contrast, the invasives had shorter payback times $(\mathrm{PT})$ and lower carbon-to-nitrogen ratios $(\mathrm{C}: \mathrm{N})$ than cooccurring natives. The invasive and native species were not significantly different in leaf-construction costs (CC), leaf tissue density (Density), leaf-potassium concentrations $\left(K_{\mathrm{m}}\right)$, leaf mass-loss rates (Loss-M), photosynthetic water-use efficiency (PWUE), dark respiration rates $\left(R_{\mathrm{d}}\right)$, specific leaf area (SLA), and leaf thickness (Thickness).

For all 12 traits that showed significant differences between all invasive and native species, the overall differences were affected by other factors besides sampling error, as showed by the significant heterogeneities in the effect sizes of the 12 traits among the invasive-native species pairs (for $Q_{T}, P<0.05$; Suppl. material 2: Table S4). We focused on these 12 traits in the following sections.

\section{Effects of invasiveness of the invasive species}

Invasiveness of the invasive species influenced the differences between the invasive and native species in Loss- $\mathrm{N}\left(Q_{\mathrm{M}}=8.99, P=0.011\right)$, but not in other 11 


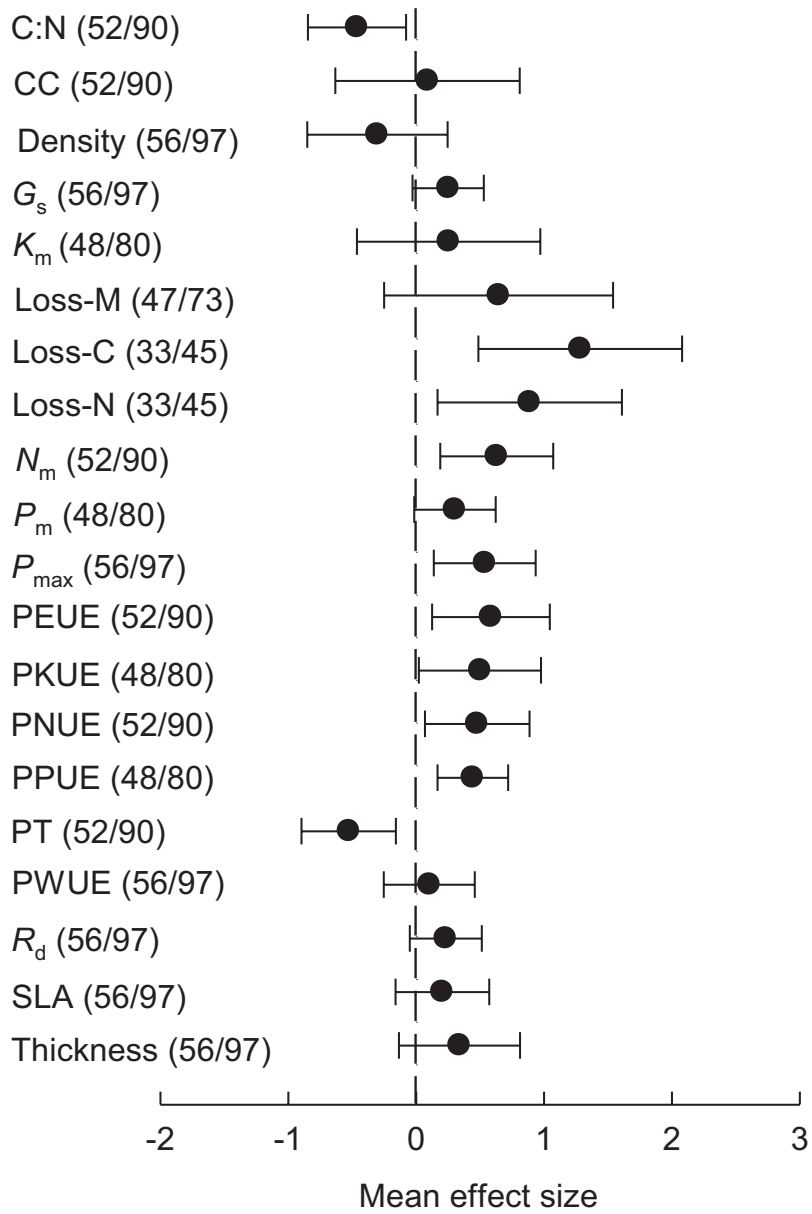

Figure 2. Phylogenetically informed mean effect sizes (Hedges' $d$ ) and their $95 \%$ confidence intervals showing the overall differences in 20 leaf functional traits between the invasive and native species. The figures between brackets on the left indicate the number of the invasive species included and the number of species pairs compared, respectively. C:N, leaf-carbon-to-nitrogen ratio; CC, leaf-construction costs (g glucose $\left.\mathrm{g}^{-1}\right)$; Density, leaf tissue density $\left(\mathrm{g} \mathrm{cm}^{-3}\right) ; G_{\mathrm{s}}$, mass-based leaf stomatal conductance $\left(\mathrm{mmol} \mathrm{g}^{-1} \mathrm{~s}^{-1}\right) ; K_{\mathrm{m}}$, leaf-potassium concentration ( $\left.\mathrm{mg} \mathrm{g}^{-1}\right)$; Loss-M, leaf-mass-loss rate (\%); Loss-C, leaf-carbon-loss rate (\%); Loss- $\mathrm{N}$, leafnitrogen-loss rate (\%); $N_{\mathrm{m}}$, leaf-nitrogen concentration $\left(\mathrm{mg} \mathrm{g}^{-1}\right) ; P_{\mathrm{m}}$, leaf-phosphorus concentration $\left(\mathrm{mg} \mathrm{g}^{-1}\right)$; $P_{\text {max }}$, mass-based leaf light saturated photosynthetic rate $\left(\mu \mathrm{mol} \mathrm{g}^{-1} \mathrm{~s}^{-1}\right)$; PEUE, leaf photosynthetic energy-use efficiency $\left(\mu \mathrm{mol} \mathrm{g} \mathrm{g}^{-1}\right)$; PKUE, photosynthetic potassium-use efficiency $\left(\mu \mathrm{mol} \mathrm{g}{ }^{-1} \mathrm{~s}^{-1}\right)$; PNUE, photosynthetic nitrogen-use efficiency $\left(\mu \mathrm{mol} \mathrm{g}{ }^{-1} \mathrm{~s}^{-1}\right)$; PPUE, photosynthetic phosphorus-use efficiency $\left(\mu \mathrm{mol} \mathrm{g} \mathrm{g}^{-1} \mathrm{~s}^{-1}\right)$; PT, leaf-payback time (d); PWUE, photosynthetic water-use efficiency $\left(\mu \mathrm{mol} \mathrm{mol}^{-1}\right) ; R_{\mathrm{d}^{\mathrm{d}}}$, mass-based leaf dark respiration rate $\left(\mu \mathrm{mol} \mathrm{g} \mathrm{s}^{-1}\right)$; SLA, specific leaf area $\left(\mathrm{cm}^{2} \mathrm{mg}^{-1}\right)$; Thickness, leaf thickness $(\mathrm{mm})$.

traits (Suppl. material 2: Table S4). As expected, the strongly or moderately invasive species had significantly higher Loss- $\mathrm{N}$ than their co-occurring natives, while the difference disappeared when comparing weakly invasive species with their cooccurring natives (Fig. 3A). Also consistent with our expectation, the magnitudes 
of the differences between the invasive and native species in Loss- $\mathrm{N}$ decreased when gradually and randomly excluding strongly to moderately invasive species from the species pool (Fig. 4; see downwards). The difference became not significant when 10 of the strongly invasive species were excluded from the species pool. Furthermore, invasives were even lower in Loss- $\mathrm{N}$ than natives (although not significant) when only the weakly (or including four moderately) invasive species were compared with their co-occurring natives (Figs 3A, 4). However, effects of the exclusions of moderately or even weakly invasive species were relatively small (Fig. 4; see upwards).

Invasiveness of the invasive species also influenced the differences in other 11 traits between the invasive and native species (Suppl. material 1: Figs S2, S3), although its effects on these traits were not detected in our mixed-effects models (Suppl. material 2: Table S4). The differences in these traits were not significant when only the weakly (or including few moderately) invasive species were compared with their co-occurring natives. In addition, the magnitudes of the differences in $P_{\text {max }}$ PNUE, and Loss-C increased when gradually excluding weakly to moderately invasive species from the species pool.

A

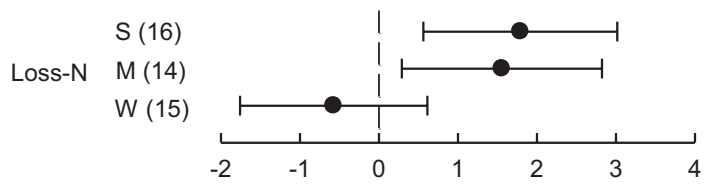

B

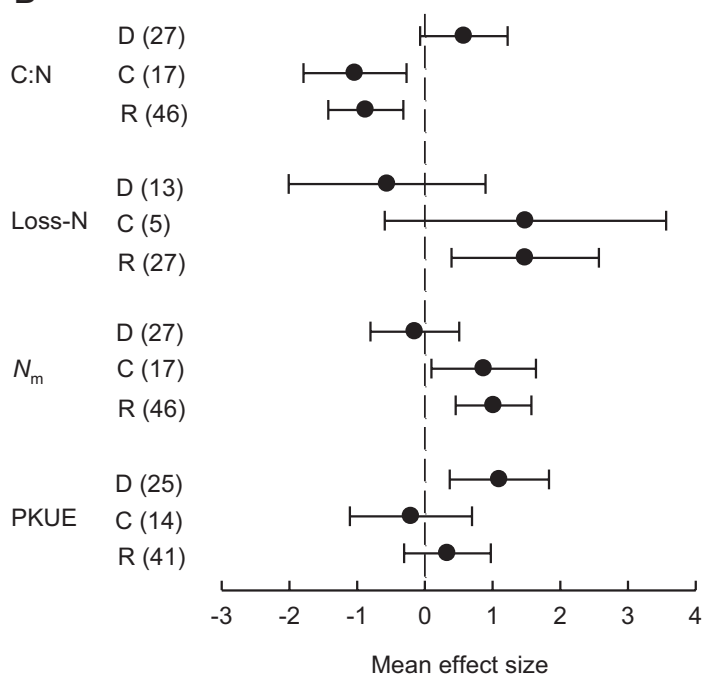

Figure 3. Effects of invasiveness of the invasive species $(\mathbf{A})$ and abundances of the natives $(\mathbf{B})$ on differences between invasive and native species, respectively. S, M and W indicate that strongly, moderately and weakly invasive species are compared with their co-occurring natives, respectively. D, C and R indicate that widespread dominant, common and rare natives are compared with their co-occurring invasives, respectively. The traits whose interspecific differences were not affected by those factors were not shown. See Figure 1 for trait abbreviations. The figures between brackets on the left indicate the numbers of species pairs included in the analyses. 


\section{Effects of abundances of the native species}

Abundances of the natives significantly influenced the differences between the invasive and native species in C:N $\left(Q_{\mathrm{M}}=18.66, P<0.001\right)$, Loss- $\mathrm{N}\left(Q_{\mathrm{M}}=6.00, P=0.049\right), N_{\mathrm{m}}$ $\left(Q_{\mathrm{M}}=10.13, P=0.006\right)$, and $\operatorname{PKUE}\left(Q_{\mathrm{M}}=7.01, P=0.030\right)$, but not in other eight traits (Suppl. material 2: Table S4). The invasives had similar C:N, Loss-N and $N_{\mathrm{m}}$, and higher PKUE when compared with co-occurring widespread dominant natives (Fig. 3B). When compared with rare or common natives, the invasives had significantly lower $\mathrm{C}: \mathrm{N}$, higher Loss-N (not significant with common natives) and $N_{\mathrm{m}}$, and similar PKUE. Also consistent with our expectation, the magnitudes of the differences in C:N, Loss- $\mathrm{N}$, and $N_{\mathrm{m}}$ decreased when gradually excluding rare to common natives from the species pool (Fig. 5; see upwards), while increased when gradually excluding dominant to common natives (Fig. 5; see downwards).

We also detected the effects of the abundance of the natives on other eight traits through species exclusion approach (Suppl. material 1: Figs S4, S5), although its effects on these traits were not detected in our mixed-effects models (Suppl. material 2: Table S4). The differences in these traits disappeared when the invasives were compared with their cooccurring dominant and common natives. In addition, the magnitudes of the differences in $P_{\max }$, PEUE, and PPUE decreased when gradually excluding rare to common natives from the species pool, while increased when gradually excluding dominant to common natives (Suppl. material 1: Fig. S4).

\section{Effects of invasive elsewhere of the native species}

Contrary to our expectation, whether the natives were invasive elsewhere did not influence the differences in the 12 traits between the invasive and native species (Suppl. material 2: Table S4).

\section{Discussion}

\section{Overall differences between invasive and native species}

Our phylogenetically controlled within-study meta-analyses showed that the invasive relative to the co-occurring native species had significantly higher leaf nutrient concentrations, photosyntheses, photosynthetic nutrients- and energy-use efficiencies, and higher leaf litter decomposition rates, but lower carbon-to-nitrogen ratios and shorter payback time of leaf construction cost (Fig. 2). Our results regarding leaf nitrogen and phosphorus concentrations and leaf carbon to nitrogen ratio were consistent with those from all multi-species comparisons and reviews that compared the three traits (Suppl. material 2: Table S1; Baruch and Goldstein 1999; Leishman et al. 2007; Heberling and Fridley 2013; Huang et al. 2020). Our results regarding photosynthetic energy-use efficiency and payback time of leaf construction cost were also in line with those of Heberling and 


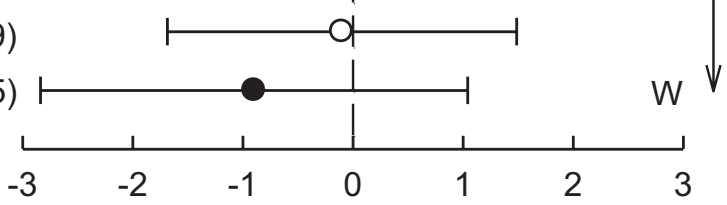

Mean effect size

Figure 4. Effects of invasiveness of the invasive species on the differences between invasive and native species from a subsets of the species pairs in leaf-litter nitrogen loss rate (Loss-N). "All" on the right indicates that all measured species pairs were included in the analysis. Arrows upwards from "All" indicate that species pairs containing weak and moderately invasive plants were excluded gradually and randomly from the analyses; arrows downwards from "All" indicate that species pairs containing strongly and moderately invasive plants were excluded gradually. " $S$ " indicates that only the strongly invasive plants were compared with their co-occurring natives; "SM" indicates that both strongly and moderately invasive plants were compared with their co-occurring natives; "W" indicates that only the weakly invasive plants were compared with their co-occurring natives; "WM" indicates that both weakly and moderately invasive plants were compared with their co-occurring natives; open circles indicate the differences when a random set of species pairs was excluded. The figures between brackets on the left of each panel indicate the numbers of species pairs included in the analyses.

Fridley (2013), which was the only multi-species comparison of these traits between invasive and native species. These traits may contribute more to the invasion success of invasive species than the others (Liu et al. 2017; Huang et al. 2020).

For other traits, however, many multi-species comparisons and reviews reported inconsistent results with ours. For example, Daehler (2003) and Baruch and Goldstein (1999) found similar photosynthesis and photosynthetic nitrogen-use efficiency for invasive and native species, respectively. Higher specific leaf area was found for invasive species in two multi-species comparisons (Baruch and Goldstein 1999; Leishman et al. 2007) and three reviews (Pyšek and Richardson 2007; van Kleunen et al. 2010; Castro- 


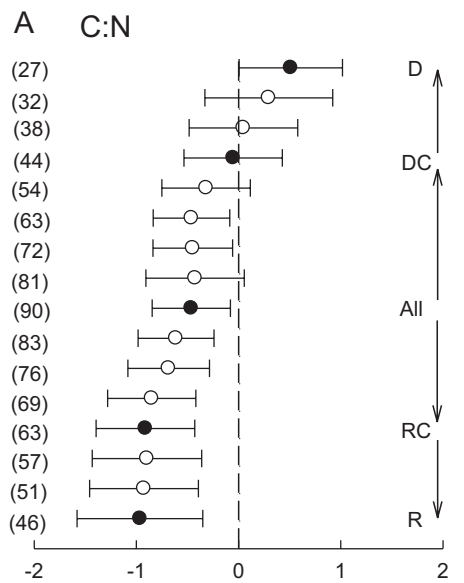

\section{B Loss-N}

(13)

(18)<smiles></smiles><smiles>[Te][Te]I</smiles><smiles>C1CCOC1</smiles><smiles>C1COC1</smiles>

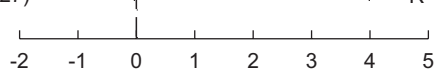

C $\quad N_{\mathrm{m}}$

D PKUE

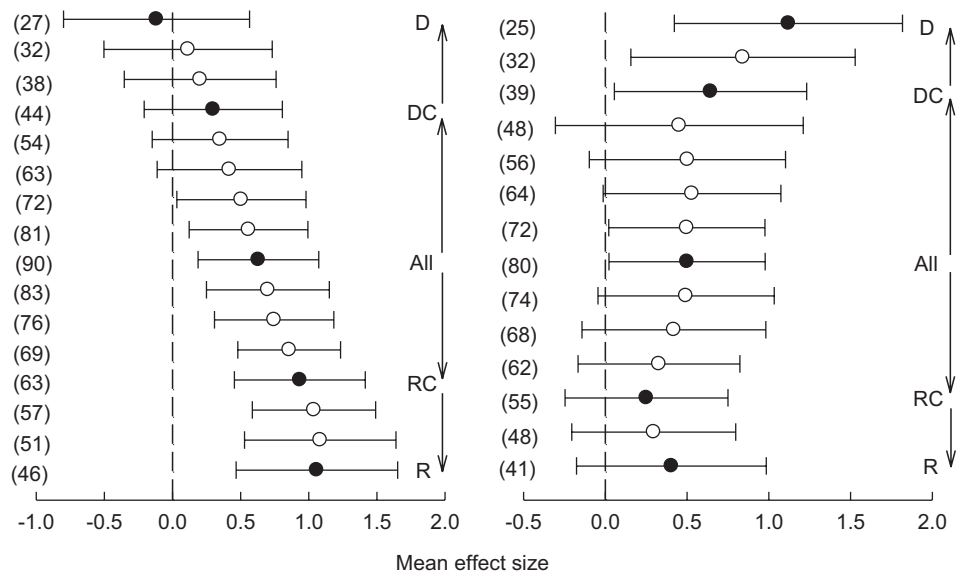

Figure 5. Effects of abundances of the native species on the differences between invasive and native species from a subset of the species pairs in leaf-carbon-to-nitrogen ratio (C:N), leaf-litter nitrogen loss rate (Loss-N), leaf-nitrogen concentration $\left(N_{\mathrm{m}}\right)$, and photosynthetic potassium-use efficiency (PKUE). "All" on the right of each panel indicates that all measured species pairs were included in the analysis. Arrows upwards from "All" indicate that species pairs containing rare and common natives were excluded gradually and randomly from the analyses; arrows downwards from "All" indicate that species pairs containing widespread dominant and common natives were excluded gradually. " $\mathrm{D}$ " indicates that only the widespread dominant natives were compared with their co-occurring invasives; "DC" indicates that both widespread dominant and common natives were compared with their co-occurring invasives; " $\mathrm{R}$ " indicates that only the rare natives were compared with their co-occurring invasives; "RC" indicates that both rare and common natives were compared with their co-occurring invasives; open circles indicate the differences when a random set of species pairs was excluded. The figures between brackets on the left of each panel indicate the numbers of species pairs included in the analyses.

Díez et al. 2014), while similar values of this trait were found for invasive and native species in three multi-species comparisons (Heberling and Fridley 2013; Divíšek et al. 2018; Huang et al. 2020) and a review (Leishman et al. 2007). It is hard to know the reasons for the discrepant results of our studies and those of previous ones, because there 
are many factors that differ between the studies. Our study controlled phylogenetic relatedness between the invasive and native species, which may increase the objectivity of the results. If we did not control the phylogenetic relatedness, the comparative results would be differences in four traits (C:N, leaf density, stomatal conductance, and phosphorus concentration; Suppl. material 1: Fig. S6). We also controlled other potentially influencing factors such as latitudes and altitudes of sample sites. The identical protocol was applied for all species and in all sites in our study, while different protocols were used in different case studies that were included in the aforementioned reviews. Another advantage of our study over reviews is that our results are not affected by publication biases (Rosenberg et al. 2000; Leimu and Koricheva 2004; Koricheva and Gurevitch 2014). The higher frequency of inconsistent results among reviews relative to experimental studies (in $80 \%$ vs $64 \%$ of the traits; Suppl. material 2: Table S1) may provide indirect evidence for the confounding effects of publication biases as well as other factors (such as experimental protocols).

Most importantly and interestingly, we found that identities of both the invasive and the native species influenced the differences between the invasive and native species, which may give another explanation for the inconsistencies in the results of previous and current studies.

\section{Effects of identities of the invasive and native species}

Our study provided strong evidence that invasiveness of exotic species and abundances of natives influenced the differences between invasive and native species, and showed how they influenced the differences. As expected, strongly or moderately invasive species had higher leaf nitrogen-loss rates than co-occurring natives, while the difference disappeared when comparing weakly invasive species with co-occurring natives (Fig. 3A). In addition, the magnitude of the difference decreased when gradually and randomly removing invasives with strong to moderate invasiveness from the species pool (Fig. 4). Also like expectation, invasives were significantly different from rare or common natives in leaf carbon-to-nitrogen ratios (lower), nitrogen-loss rates (higher) and nitrogen concentrations (higher), while similar with widespread dominant natives (Fig. 3B). The magnitudes of the differences in these traits also increased when removing common to dominant natives from the species pool, while decreased when removing rare to common natives (Fig. 5). Similar patterns to the aforementioned were also found for other traits (Suppl. material 1: Figs S2-S5). Consistent with our results, McDowell (2002) found that invasive Rubus discolor has higher leaf nitrogen concentration than native congener $R$. leucodermis but not than native $R$. ursinus, which may be due to the fact that the $R$. ursinus is a ruderal with high abundance in habitats (Caplan and Yeakley 2013). Huang et al. (2020) found that invasives had higher leaf nitrogen concentrations than co-occurring natives, but not higher than cooccurring non-invasive aliens. Recently, Huang (2020) found that invasives had higher leaf nutrient concentrations and photosyntheses than co-occurring natives with low abundances in communities, but not than dominant natives with high 
abundances. Similarly, species identities also influenced the differences in competitive ability between invasive and native species (Zhang and van Kleunen 2019; Zheng et al. 2020). Our results clearly show the effects of species identities on trait differences between invasive and native species, and give a possible explanation for the discrepant results in references, which compared invasives with different invasiveness and natives with different abundances (Baruch and Goldstein 1999; Daehler 2003; Leishman et al. 2007; Pyšek and Richardson 2007; van Kleunen et al. 2010; Castro-Díez et al. 2014).

Our results indicate that it is most likely to detect significant difference between strongly invasive species and rare natives, and the magnitude of the difference is the greatest among the comparisons of strong to weak invasives and rare to dominant natives. In contrast, it is most unlikely to find trait advantage for invasives when comparing weakly invasive species with widespread dominant natives. In our study, a few strongly and weakly invasive species were occasionally compared with rare and dominant natives (four combinations). By analyzing the invasive-native differences, respectively, we found that strongly invasive species were significantly different to rare natives in a third of the traits, while no significant differences were found when comparing weakly invasive species with either rare or dominant natives, and comparing strongly invasive species with dominant natives (Data not shown). Weakly invasive species (especially for annuals) may not have trait advantages over natives, and their invasions may merely be due to vacant niche in recipient habitats (Rhymer and Simberloff 1996). Significant correlations between leaf functional traits and species abundances have been documented (Zhang et al. 2018; Huang 2020), which indicate that dominant natives may have some trait advantages over rare natives, and thus are more ecologically similar to invasives than to rare natives (Caplan and Yeakley 2013; Zhang and van Kleunen 2019; Huang 2020). Widespread dominant natives may even have trait advantages to compete with or even suppress alien invasives (Canessa et al. 2018).

Our study indicates that results of comparative studies, irrespective of the number of species included, may always be species-specific and environment-dependent. Discrepant results between our current and previous multi-species comparisons and reviews may be at least partially originated from the species-specific effects (Baruch and Goldstein 1999; Daehler 2003; Leishman et al. 2007; Pyšek and Richardson 2007; van Kleunen et al. 2010; Castro-Díez et al. 2014; Huang 2020). Thus, it is difficult to reveal common traits (if any) shared by invasives through multi-species comparisons or meta-analyses of published data. In the future, we would do better to compare functional traits of invasive and native species at both species and community levels in wild communities, rather than compare broadly across many species pairs. We should also account for potential influencing factors such as invasiveness, residence time and invasion stages of invasives; abundances of natives; resource availability, enemy regimes, plant species diversity, functional diversity and phylogenetic diversity in communities. In this way, we may better understand the traits promoting invasion in both species and community levels. 


\section{Conclusion}

Overall, the invasive plants had significantly higher leaf nutrient concentrations, photosyntheses, photosynthetic nutrients- and energy-use efficiencies, and higher leaf litter decomposition rates, but shorter payback time of leaf construction cost and lower carbon-to-nitrogen ratios than co-occurring natives. More importantly and interestingly, the differences were affected significantly by identities of both the invasive and the native species. Furthermore, the magnitudes of the differences in some traits decreased or even reversed when gradually excluding a random subset of strongly to moderately invasive species from the species pool. Removing rare to common natives produced the same effect, while exclusion of weakly to moderately invasive species and dominant to common natives enhanced the differences. Our results provide a possible explanation for the discrepant results between our current and previous studies, and indicate that it may be unlikely to obtain general leaf traits (if any) for invasives through multi-species comparisons, which are species-specific and environment-dependent. In the future, we should compare invasive and native species at both species and community levels in different habitats, and account for possible influencing factors.

\section{Acknowledgements}

This study was supported by the National Natural Science Foundation of China (31971557, 32171666, 32171662 and 31670545) and the National Key R\&D Program of China (2017YFC1200101). We are grateful to Shu-Mei Jiang, Zhi-Dong Xu, Guo-Hua Ding, Dong-Ping Dong, Jing-Gang Zheng, Wen-Guo Wang and Zhan-Gen $\mathrm{Lu}$ for helpful assistance in field measurements.

\section{References}

Bakker MA, Carreño-Rocabado G, Poorter L (2011) Leaf economics traits predict litter decomposition of tropical plants and differ among land use types. Functional Ecology 25: 473-483. https://doi.org/10.1111/j.1365-2435.2010.01802.x

Baruch Z, Goldstein G (1999) Leaf construction cost, nutrient concentration, and net $\mathrm{CO}_{2}$ assimilation of native and invasive species in Hawaii. Oecologia 121: 183-192. https://doi. org/10.1007/s004420050920

Canessa R, Saldaña A, Ríos RS, Gianoli E (2018) Functional trait variation predicts distribution of alien plant species across the light gradient in a temperate rainforest. Perspectives in Plant Ecology, Evolution and Systematics 32: 49-55. https://doi.org/10.1016/j.ppees.2018.04.002

Caplan JS, Yeakley JA, (2013) Functional morphology underlies performance differences among invasive and non-invasive ruderal Rubus species. Oecologia 173: 363-374. https:// doi.org/10.1007/s00442-013-2639-2 
Castro-Díez P, Godoy O, Alonso A, Gallardo A, Saldaña A (2014) What explains variation in the impacts of exotic plant invasions on the nitrogen cycle? A meta-analysis. Ecology Letters 17: 1-12. https://doi.org/10.1111/ele.12197

Cornwell WK, Cornelissen JHC, Amatangelo K, Dorrepaal E, Eviner VT, Godoy O, Hobbie SE, Hoorens B, Kurokawa H, Pérez-Harguindeguy N, Quested HM, Santiago LS, Wardle DA, Wright IJ, Aerts R, Allison SD, van Bodegom P, Brovkin V, Chatain A, Callaghan TV, Díaz S, Garnier E, Gurvich DE, Kazakou E, Klein JA, Read J, Reich PB, Soudzilovskaia NA, Vaieretti MV, Westoby M (2008) Plant species traits are the predominant control on litter decomposition rates within biomes worldwide. Ecology Letters 11: 1065-1071. https://doi.org/10.1111/j.1461-0248.2008.01219.x

Daehler CC (2003) Performance comparisons of co-occurring native and alien invasive plants: implications for conservation and restoration. Annual Review of Ecology, Evolution, and Systematics 34: 183-211. https://doi.org/10.1146/annurev.ecolsys.34.011802.132403

Divíšek J, Chytrý M, Beckage B, Gotelli NJ, Lososová Z, Pyšek P, Richardson DM, Molofsky J (2018) Similarity of introduced plant species to native ones facilitates naturalization, but differences enhance invasion success. Nature Communications 9: 4631. https://doi. org/10.1038/s41467-018-06995-4

Feng Y-L (2008) Photosynthesis, nitrogen allocation and specific leaf area in invasive Eupatorium adenophorum and native Eupatorium japonicum grown at different irradiances. Physiologia Plantarum 133: 318-326. https://doi.org/10.1111/j.1399-3054.2008.01072.x

Feng Y-L, Auge H, Ebeling SK (2007) Invasive Buddleja davidii allocates more nitrogen to its photosynthetic machinery than five native woody species. Oecologia 153: 501-510. https://doi.org/10.1007/s00442-007-0759-2

Feng Y-L, Lei Y-B, Wang R-F, Callaway RM, Valiente-Banuet A, Inderjit, Li Y-P, Zheng Y-L (2009) Evolutionary tradeoffs for nitrogen allocation to photosynthesis versus cell walls in an invasive plant. Proceedings of the National Academy of Sciences of the United States of America 106: 1853-1856. https://doi.org/10.1073/pnas.0808434106

Feng Y-L, Li Y-P, Wang R-F, Callaway RM, Valiente-Banuet A, Inderjit (2011) A quicker return energy-use strategy by populations of a subtropical invader in the non-native range: a potential mechanism for the evolution of increased competitive ability. Journal of Ecology 99: 1116-1123. https://doi.org/10.1111/j.1365-2745.2011.01843.x

Heberling JM, Fridley JD, (2013) Resource-use strategies of native and invasive plants in Eastern North American forests. New Phytologist 200: 523-533. https://doi.org/10.1111/nph.12388

Huang K (2020) Species- and community level differences in leaf functional traits and nutrient cycles between invasive and native plants and the effects of environments. PhD thesis, Shenyang Agricultural University, Shenyang.

Huang K, Kong D-L, Lu X-R, Feng W-W, Liu M-C, Feng Y-L (2020) Lesser leaf herbivore damage and structural defenses and greater nutrient concentrations for invasive alien plants: evidence from 47 pairs of invasive and non-invasive plants. Science of the Total Environment 723: 137829. https://doi.org/10.1016/j.scitotenv.2020.137829

Hulme PE, Bernard-Verdier M (2018) Comparing traits of native and alien plants: can we do better?. Functional Ecology 32: 117-125. https://doi.org/10.1111/1365-2435.12982

Inderjit, Evans H, Crocoll C, Bajpai D, Kaur R, Feng YL, Silva C, Carreón JT, Valiente-Banuet A, Gershenzon J, Callaway RM (2011) Volatile chemicals from leaf litter are associ- 
ated with invasiveness of a Neotropical weed in Asia. Ecology 92: 316-324. https://doi. org/10.1890/10-0400.1

Kobe RK, Lepczyk CA, Iyer M (2005) Resorption efficiency decreases with increasing green leaf nutrients in a global data set. Ecology 86: 2780-2792. https://doi.org/10.1890/04-1830

Koricheva J, Gurevitch J (2014) Uses and misuses of meta-analysis in plant ecology. Journal of Ecology 102: 828-844. https://doi.org/10.1111/1365-2745.12224

Leimu R, Koricheva J (2004) Cumulative meta-analysis: a new tool for detection of temporal trends and publication bias in ecology. Proceedings of the Royal Society of London B: Biological Sciences 271: 1961-1966. https://doi.org/10.1098/rspb.2004.2828

Leishman MR, Haslehurst T, Ares A, Baruch Z (2007) Leaf trait relationships of native and invasive plants: community- and global-scale comparisons. New Phytologist 176: 635-643. Leung HC (1986) Aspects of leaflitter decomposition in Kandelia candel(L.) Druce. M. Phil. thesis, University of Hong Kong, Hong Kong. https://doi.org/10.1111/j.1469-8137.2007.02189.x

Li YH (1998) China weed. China Agriculture Press, Beijing. [In Chinese]

Li Y-P, Feng Y-L, Chen Y-J, Tian Y-H (2015) Soil microbes alleviate allelopathy of invasive plants. Science Bulletin 60: 1083-1091. https://doi.org/10.1007/s11434-015-0819-7

Liu M-C, Kong D-L, Lu X-R, Huang K, Wang S, Wang W-B, Qu B, Feng Y-L (2017) Higher photosynthesis, nutrient- and energy-use efficiencies contribute to invasiveness of exotic plants in a nutrient poor habitat in northeast China. Physiologia Plantarum 160: 373-382. https://doi.org/10.1111/ppl.12566

Liu Y, van Kleunen M (2017) Responses of common and rare aliens and natives to nutrient availability and fluctuations. Journal of Ecology 105: 1111-1122. https://doi. org/10.1111/1365-2745.12733

Ma J (2013) The checklist of the Chinese invasive plants. Higher Education Press, Beijing. [In Chinese]

McDowell SC (2002) Photosynthetic characteristics of invasive and noninvasive species of Rubus (Rosaceae). American Journal of Botany 89: 1431-1438. https://doi.org/10.3732/ ajb.89.9.1431

Pyšek P, Richardson DM (2007) Traits associated with invasiveness in alien plants: where do we stand? In: Nentwig, W. ed. Biological Invasions. Springer, New York, 97-125. https://doi. org/10.1007/978-3-540-36920-2_7

R Core Team (2018) R: a language and environment for statistical computing. R Foundation for Statistical Computing, Vienna. http://www.R-project.org/

Rhymer JM, Simberloff D (1996) Extinction by Hybridization and Introgression. Annual Review of Ecological Systems 27: 83-109. https://doi.org/10.1146/annurev.ecolsys.27.1.83

Richardson DM, Pyšek P (2006) Plant invasions: merging the concepts of species invasiveness and community invasibility. Progress in Physical Geography 30: 409-431. https://doi. org/10.1191/0309133306pp490pr

Rosenberg MS, Adams DC, Gurevitch J (2000) MetaWin: statistical software for meta-analysis. Version 2.0. Sinauer Associates, Sunderland, MA.

Seebens H, Blackburn TM, Dyer EE, Genovesi P, Hulme PE, Jeschke JM, Pagad S, Pyšek P, Winter M, Arianoutsou M, Bacher S, Blasius B, Brundu G, Capinha C, Celesti-Grapow L, Dawson W, Dullinger S, Fuentes N, Jäger H, Kartesz J, Kenis M, Kreft H, Kühn I, Lenzner B, Liebhold A, Mosena A, Moser D, Nishino M, Pearman D, Pergl J, Rabitsch W, Rojas- 
Sandoval J, Roques A, Rorke S, Rossinelli S, Roy HE, Scalera R, Schindler S, Štajerová K, Tokarska-Guzik B, van Kleunen M, Walker K, Weigelt P, Yamanaka T, Essl F (2017) No saturation in the accumulation of alien species worldwide. Nature Communications 8: 14435. https://doi.org/10.1038/ncomms14435

Swenson NG, (2014) Functional and phylogenetic ecology in R. Springer, New York. https:// doi.org/10.1007/978-1-4614-9542-0

Tam NFY, Vrijmoed LLP, Wong YS (1990) Nutrient dynamics associated with leaf decomposition in small subtropical mangrove community in Hong Kong. Bulletin of Marine Science 47: 68-78.

Tamura K, Stecher G, Peterson D, Filipski A, Kumar S (2013) MEGA6: molecular evolutionary genetics analysis version 6.0. Molecular Biology and Evolution 30: 2725-2729. https:// doi.org/10.1093/molbev/mst197

van Kleunen M, Dawson W, Maurel N (2015b) Characteristics of successful alien plants. Molecular Ecology 24: 1954-1968. https://doi.org/10.1111/mec.13013

van Kleunen M, Dawson W, Essl F, Pergl J, Winter M, Weber E, Kreft H, Weigelt P, Kartesz J, Nishino M, Antonova LA, Barcelona JF, Cabezas FJ, Cárdenas D, Cárdenas-Toro J, Castaño N, Chacón E, Chatelain C, Ebel AL, Figueiredo E, Fuentes N, Groom QJ, Henderson L, Inderjit, Kupriyanov A, Masciadri S, Meerman J, Morozova O, Moser D, Nickrent DL, Patzelt A, Pelser PB, Baptiste MP, Poopath M, Schulze M, Seebens H, Shu W, Thomas J, Velayos M, Wieringa JJ, Pyšek P (2015a) Global exchange and accumulation of non-native plants. Nature 525: 100-103. https://doi.org/10.1038/ nature 14910

van Kleunen M, Schlaepfer DR, Glättli M, Fischer M (2011) Preadapted for invasiveness: do species traits or their plastic responses to shading differ between invasive and non-invasive plant species in their native range? Journal of Biogeography 38: 1294-1304. https://doi. org/10.1111/j.1365-2699.2011.02495.x

van Kleunen M, Weber E, Fischer M (2010) A meta-analysis of trait differences between invasive and non-invasive plant species. Ecology Letters 13: 235-245. https://doi.org/10.1111/ j.1461-0248.2009.01418.x

Viechtbauer W (2010) Conducting meta-analyses in R with the metafor package. Journal of Statistical Software 36: 1-48. https://doi.org/10.18637/jss.v036.i03

Wang W-B, Wang R-F, Lei Y-B, Liu C, Han L-H, Shi X-D, Feng Y-L (2013) High resource capture and use efficiency and prolonged growth season contribute to invasiveness of Eupatorium adenophorum. Journal of Plant Ecology 214: 857-868. https://doi.org/10.1007/ s11258-013-0214-x

Zhang H, John R, Zhu S, Liu H, Xu Q, Wei Q, Liu K, Chen HYH, Ye Q (2018) Shifts in functional trait-species abundance relationships over secondary subalpine meadow succession in the Qinghai-Tibetan Plateau. Oecologia 188: 547-557. https://doi.org/10.1007/ s00442-018-4230-3

Zhang Z, van Kleunen M (2019) Common alien plants are more competitive than rare natives but not than common natives. Ecology Letters 22: 1378-1386. https://doi.org/10.1111/ ele. 13320 
Zhao Y-Z, Liu M-C, Feng Y-L, Wang D, Feng W-W, Clay K, Durden LA, Lu XR, Wang S, Wei X-L, Kong, D-L (2020) Release from below- and aboveground natural enemies contributes to invasion success of a temperate invader. Plant Soil 452: 19-28. https://doi.org/10.1007/ s11104-020-04520-5

Zheng Y-L, Feng Y-L, Zhang L-K, Callaway RM, Valiente-Banuet A, Luo D-Q, Liao Z-Y, Lei Y-B, Barclay GF, Silva-Pereyra C (2015) Integrating novel chemical weapons and evolutionarily increased competitive ability in success of a tropical invader. New Phytologist 205: 1350-1359. https://doi.org/10.1111/nph.13135

Zheng Y-L, Liao Z-Y, Li W-T, Wang R-F, Li L, Yang A-D, Zheng Y-G, Feng Y-L (2020) The effect of resource pulses on the competitiveness of a tropical invader depends on identity of resident species and resource type. Acta Oecologia 102: 103507. https://doi.org/10.1016/j. actao.2019.103507

\section{Supplementary material I}

\section{Figure S1-S7}

Authors: Ming-Chao Liu, Ting-Fa Dong, Wei-Wei Feng, Bo Qu, De-Liang Kong, Mark van Kleunen, Yu-Long Feng

Data type: docx. file

Explanation note: Figure S1. Sample sites spanning $24^{\circ}$ latitudes from tropical to temperate zones in China. Figure S2. Topology of the maximum likelihood phylogenetic tree for all studied species. Figure S3. Effects of invasiveness of the invasive plants on the differences in $P_{\max }$, PEUE, PNUE, PPUE, PT, and Loss-C between invasive and native plants from a subsets of the species pairs. Figure S4. Effects of invasiveness of the invasive plants on the differences in C:N $G_{\mathrm{s}}, N_{\mathrm{m}}, P_{\mathrm{m}}$, and PKUE between invasive and native plants from a subsets of the species pairs. Figure S5. Effects of abundances of the native plants on the differences in $P_{\max }$, PEUE, PNUE, PPUE, PT, and Loss-C between invasive and native plants from a subsets of the species pairs. Figure S6. Effects of abundances of the native plants on the differences in $G_{s}$ and $P_{\mathrm{m}}$ between invasive and native plants from a subsets of the species pairs. Figure S7. Phylogenetically non-informed mean effect sizes (Hedges'd) and their $95 \%$ confidence intervals showing the overall differences in 20 leaf functional traits between the invasive and native species.

Copyright notice: This dataset is made available under the Open Database License (http://opendatacommons.org/licenses/odbl/1.0/). The Open Database License $(\mathrm{ODbL})$ is a license agreement intended to allow users to freely share, modify, and use this Dataset while maintaining this same freedom for others, provided that the original source and author(s) are credited.

Link: https://doi.org/10.3897/neobiota.71.71385.suppl1 


\section{Supplementary material 2}

\section{Table S1, S2, S4}

Authors: Ming-Chao Liu, Ting-Fa Dong, Wei-Wei Feng, Bo Qu, De-Liang Kong, Mark van Kleunen, and Yu-Long Feng

Data type: docx. file

Explanation note: Table S1. Differences in leaf functional traits between invasive and native or non-invasive alien plants in references that compared multiple species. Table S2. Background information on the seven sample sites. Table S4. Effects of identities of the invasive and native plants compared on the invasive-native differences.

Copyright notice: This dataset is made available under the Open Database License (http://opendatacommons.org/licenses/odbl/1.0/). The Open Database License $(\mathrm{ODbL})$ is a license agreement intended to allow users to freely share, modify, and use this Dataset while maintaining this same freedom for others, provided that the original source and author(s) are credited.

Link: https://doi.org/10.3897/neobiota.71.71385.suppl2

\section{Supplementary material 3}

\section{Table S3}

Authors: Ming-Chao Liu, Ting-Fa Dong, Wei-Wei Feng, Bo Qu, De-Liang Kong, Mark van Kleunen, and Yu-Long Feng

Data type: excel file

Explanation note: Table S3. Background information on the studied species and the values of 20 leaf functional traits for these species.

Copyright notice: This dataset is made available under the Open Database License (http://opendatacommons.org/licenses/odbl/1.0/). The Open Database License $(\mathrm{ODbL})$ is a license agreement intended to allow users to freely share, modify, and use this Dataset while maintaining this same freedom for others, provided that the original source and author(s) are credited.

Link: https://doi.org/10.3897/neobiota.71.71385.suppl3 